\title{
Using ArcGIS to Analyze Land Availability for Rwanda's Forest Area Expansion
}

\author{
Aline Umutoni, Wukui Wang* \\ Electronic-Commerce/Management Science and Engineering Department, School of Economics and Management, Beijing Forestry \\ University, Beijing, China \\ Email address: \\ aliton89@yahoo.fr (A. Umutoni),wangwukui@bjfu.edu.cn (Wukui Wang) \\ ${ }^{*}$ Corresponding author \\ To cite this article: \\ Aline Umutoni, Wukui Wang. Using ArcGIS to Analyze Land Availability for Rwanda's Forest Area Expansion. American Journal of \\ Environmental and Resource Economics. Vol. 3, No. 3, 2018, pp. 31-39. doi: 10.11648/j.ajere.20180303.11
}

Received: November 14, 2018; Accepted: December 18, 2018; Published: January 18, 2019

\begin{abstract}
In 2015 forest area of Rwanda was only limited to 19.5\%. Rwanda's goal is to extend its forests area 30\% of its total land area by 2035 in order to meet the requirements of International Tropical Timber Organization (ITTO) and International Union for the Conservation of Nature; ITTO/IUCN guidelines for the conservation and sustainable use of biodiversity in tropical timber production forests published in 2009. Despite reforestation efforts, there has been a drastic reduction in total forest cover in Rwanda during the recent decades. Indeed, forest resources have been under increasingly severe stress, due to high population growth, resettlement of displaced persons, related demands for agricultural land, firewood and other forest related products. Due to a high population density and high population growth, it is becoming harder and harder to meet the needs for settlement, agricultural and other economic activities hence even more difficult for afforestation land availability. In this paper we propose some areas that could be afforested or reforested in order to increase area of conservation of biodiversity in Rwanda and to comply with ITTO/IUCN guidelines of conservation areas protection and degraded area rehabilitation. We used high definition aerial images and applied Geographic Information System (GIS) to study the availability of potential land area that are likely suitable for new forest plantations. The criteria of area selection were most inconvenient land for human settlement and most inconvenient agricultural land. The results have shown that $15.14 \%$ of total country area has a slope over $30 \%$. Among the land areas with a slope over $30 \%$, forested land areas occupy $5.25 \%$. According to the results a total land area equivalent to $9.89 \%$ is available for forest plantations. This research will help to identify new and suitable land area for forest plantation and it will be useful for policy-makers in Rwanda. The government should encourage the plantation of forests in new identified areas by facilitating farmers to change their land use and discouraging other activities carried out in the identified available land areas.
\end{abstract}

Keywords: Land Use, Afforestation, Forest Restoration, Forest Site Selection

\section{Introduction}

Rwanda is a small country, where the majority of the population $(74 \%)$ most of the time practices agriculture of subsistence, according to the data of the National Institute of Statistics of Rwanda [1]. The country has a population of 12,599,982 with the highest density (507 people/ Sqkm) in the Sub-Saharan Africa [2], and the second in Africa after Mauritius [3]. Rwanda is landlocked with mountainous terrain, some of which are covered by forest, either natural or planted. The highly elevated density of Rwanda and the continuous population growth put a pressure on Rwanda's ecosystem and forests are among the oppressed resources.

Forest as defined by Food and Agriculture Organization of the United Nations [4], is "Land spanning more than 0.5 hectares with trees higher than 5 meters and a canopy cover of more than 10 percent, or trees able to reach these thresholds in situ. It does not include land that is predominantly under agricultural or urban land use". Rwanda's forest spans on the area of about $19.5 \%$ and this does not include the savanna [5].

In the past years, Rwanda's forest has gone through a period of deforestation mainly between the years 1990 and 
2000. The main drivers for Rwanda's deforestation were the subsistence agriculture and residences. A number of Rwandan refugees who were outside the country came back to the country and they had to find lands for agriculture and residences.

According to [5], while the agricultural area was 18,085 Sqkm (73.3\%), forest area occupied 4,800 Sqkm (19.5\%) over a total of 24,670 Sqkm of dried land area in Rwanda in 2015 which was its uppermost value over the past 25 years, and its lowest value was $12.89 \%$ in 1990 . Between the year 1990 and 2000, Rwanda has lost its forest at a rate of 11,400 ha/ year, which is equal to $10 \%$ and between 1990 and 2015 the rate of forest loss was of $4,600 \mathrm{ha} /$ year which is equal to $4,1 \%$. The forest loss over these years was caused by different reasons including agriculture of subsistence, the need for residential lands, wood for fire, etc.

Rwanda has different species of animals and vegetations and most of them live in natural forests or planted ones. There are about 999 known species of animals including, birds, amphibians, reptiles and mammals as indicated by the data recorded by the World Conservation Monitoring Centre. Among all these species, about $0.4 \%$ cannot be found anywhere else on the earth, which means that they only live in Rwanda. Deforestation is one of the activities that put in danger these species that only live in Rwanda and about $3.0 \%$ of these species are threatened [6].

Contrary to some countries of Latin America and Southeast Asia in which the majority of nowadays deforestation is due to the growth of industrial activities, large-scale agriculture and exhaustive logging [7], [8], Rwanda's major driver of deforestation, like in many other African countries is subsistence agriculture, fuelwood and urbanization.

In Rwanda, climate change problems and susceptibility to natural disasters have emerged recently and are causing many losses in resources and humans to the country. Population displacement and resettlement caused by the 1990-1994 conflict and genocide have caused a negative impact on the environment, significantly changing land cover and land use in various areas of the country. Refugee's movements into Rwanda resulting from conflicts in bordering countries, predominantly the Democratic Republic of the Congo (DR Congo) and Burundi, have also altered the situation of the forest the at the local level [6].

As mentioned previously, disasters and climate changes are among the problems caused by deforestation in Rwanda. Over the last decade, the occurrence and strength of natural disasters, mainly floods, have meaningfully increased and this has led to the raised rate of human casualties as well as economic and environmental losses. Flooding and landslides pose a major disaster risk in the northern and western regions of the country. Face to these challenges, some authors have proposed different solutions. Authors in [9] have stated that it is beneficial to plant forests in order to avoid flooding and landslide because forest plantations have been proved to play a role in protecting hillslopes because their roots make the soil firmer. Forests also contribute to the social services where $4 \%$ of world forest should be reserved to social services like recreational activities, tourism, etc. [10]. Avoiding deforestation, practicing sustainable forest management and restoration of deforested areas are the key potential elements that could help in avoiding damaging consequences for our planet. Forests contribute to the conservation of biodiversity and help to achieve the Sustainable Development Goals (SDGs) [11]. It has been proven that forests have a very big economic and social importance as mentioned before, because they are used for fuelwood, timber production, recreation, tourism and land conservation as forests may be planted to restore degraded land [12]. Forest plantations grow much faster than natural forests, therefore they are perceived as an increasingly important source of timber supply. More forest plantations should be put in place so that more natural forests might be saved [13].

All the authors seem to be interested in promoting forest plantations, moreover none seems to undertake the problem of forest land expansion availability. This paper tries to explore the situation in Rwanda, and shows the availability of land that could be used in order to expand forest areas. In order to establish more sustainable practice for forest management, information concerning how the land is suitable is needed to prioritize suitable forest plantation for land use development. This is vital for the intensification of land productivity and efficacy on forest management decision making process [14].

The main aim of sustainable forest management (SFM) is to guarantee the efficient production of forest resources over time, taking into consideration the environmental, economic and social values of the forest. GIS technology is an important tool for analyzing the information about the extent, productivity and conditions of the forest, and it also helps in establishing the suitable place for the placement of new forest plantations in order to assure the adequate sustainable forest management practices. Identifying potential area of forest plantation would contribute to the economic development of Rwanda as forests play a capital role in economic development of a country and social life of the population by serving as recreational centers.

It is important to conduct this study in Rwanda, because as rapid population growth and migration demand new lands in order to meet basic needs, particularly in urban areas, these needs make natural resources such as forests, wetlands and agricultural land to be changed into settlements or manufacturing areas and make these lands to be used without considering their actual potentials.

It is very vital to elaborate land use strategies that may be beneficial to the protection and conservation of natural resources in the future, and that enhance the elaborated and sustainable use of these resources in a way that is right for their potential. Land suitability evaluation is an important precondition for land use planning because the land evaluation provides a guidance for the best land use by giving information about the possibilities and limitations that may arise in using a certain land [15]. 
As Rwanda is a developing country, different emerging sectors like industrialization, housing, agriculture and infrastructure might be a threat to forest land use and sustainable forest development [14]. Consequently, it is important to conduct this study in order to clearly show the suitable land for forests expansion so that other activities may not hinder or threaten forest lands. The rest of this article is organized as follows: the next part evaluates the material and methods where a description of the study area is made. The criteria of selection of a particular area and the methods used are also described. The presentation and discussion of results will be made and the conclusion and recommendations will come at the end.

\section{Material and Methods}

\subsection{Data and Methods}

The data used for the purpose of this study are high definition aerial images taken in 2008. Satellite imageries that were taken between the year 2000 and 2016 using the LANDSAT 8 satellite were used. Elevation analysis and slope analysis of Rwanda's land has been done. GIS Digital Elevation Model (DEM) was used in order to conduct the suitability analysis and eliminate the area that don't fit within the criteria. The Digital Elevation Model map was obtained from Earth Explorer and the dataset used are Advanced Spaceborne Thermal Emission and Reflection Radiometer (ASTER) GLOBAL DEM Version 2 and Coastal National Elevation Dataset - Topobathymetric Digital Elevation Model CoNED TBDEM.

ArcGIS has been applied on the Digital Elevation Model dataset to process the elevation map. Digital Elevation Model tool of ArcGIS has been used to produce the Rwanda slope map. From the elevation map, slope analysis map has been produced. DEM has been used to create raster dataset that maps suitability for new forest plantation area. In fact, the slope map has been produced by extracting it from the elevation map and by reclassifying elevation map. The reclassification over the elevation map has been conducted in order to obtain desired number of classes of slope. It was done also in order to reduce the number of output categories that might be obtained.

A map showing the Rwanda's forest expanse has been produced, and then from the slope analysis map the areas with a slope over $30 \%$ have been identified. After producing all the maps, availability analysis of Rwanda forest has been done and a corresponding map based on the criteria set has been produced. Non-forested areas with a slope greater than $30 \%$ have been considered. These areas with such slope are normally not habitable and are considered as high-risk zones.

\subsection{Study Area}

Rwanda is a small, land-locked country. It has a mountainous terrain that gives it the famous name of 'land of a thousand hills. Although Rwanda is located in the equatorial region of the Great Lakes region in central-east of Africa, it has a tropical temperate climate because of its high altitude that reaches $2,000 \mathrm{~m}$ in average. These advantageous environmental settings give Rwanda the most elevated population density in Africa, which mostly practice subsistence agriculture and this put a high pressure on Rwanda's ecosystem. Rwanda is located between the Central and East Africa, between $1^{\circ} 04^{\prime}$ and $2^{\circ} 51^{\prime}$ latitude south and between $28^{\circ} 53^{\prime}$ and $30^{\circ} 53^{\prime}$ longitude east. It is a small country of $26,338 \mathrm{~km}^{2}$ with high mountains. Contrary to other highlands regions, temperature variations are not significant because the temperature varies between $16{ }^{\circ} \mathrm{C}$ and $24{ }^{\circ} \mathrm{C}$ in average. The higher mountains are relatively cold with temperature that can reach $10{ }^{\circ} \mathrm{C}$ during night times. The eastern part of the country with lowlands is the hottest. Rainfall are distributed over the country depending on the altitude and reach $1,200 \mathrm{~mm}$ in average each year. The rainfall ranges from $2,000 \mathrm{~mm}$ in the western and northwestern high mountains to $600 \mathrm{~mm}$ in the eastern savanna, where rainfall time are more irregular [6].

\subsection{Rwanda's Forests Expanse}

There exist significant inconsistencies in the estimation and data on forest coverage, mostly resulting largely from the way of forests classification. Rwanda's forest and woodlands are classified in four principal types:

Natural rainforests;

Forest covers in savanna landscapes;

Tree plantations and

Other trees and shrubs outside natural forest, stand tree plantations, including tree stands in agricultural lands as well as agroforestry systems.

By 2010, Rwanda's total forest cover area was 4,350 Sqkm which was equal to $18 \%$ of the total land area. The natural forest total cover was $70 \mathrm{Sqkm}$ ha which was only $2 \%$ of the total forest area. Other woodlands including forest plantations, shrubs, agroforest trees covered a total area of 61 ha. Rwanda's total forest cover has changed over years and it has known a significant decrease between the years 19902000 mainly because of the genocide in Rwanda and insecurity in neighboring countries. High population growth and high population density which results in new human settlements, turning land use into agricultural lands also contributed to Rwanda's deforestation.

The FAO report [5] showed that in 2015, Rwanda's forest and other wooded land cover was about $19.5 \%$ of the total land area. The forest cover has known some changes between the year 1990 and 2015, ranging from deforestation to afforestation. Rwanda's primary forest represents $70 \mathrm{Sqkm}$ which is equal to $1.5 \%$ of the total forest area. Other naturally regenerated forests represent $550 \mathrm{Sqkm}$ (11.5\%). 


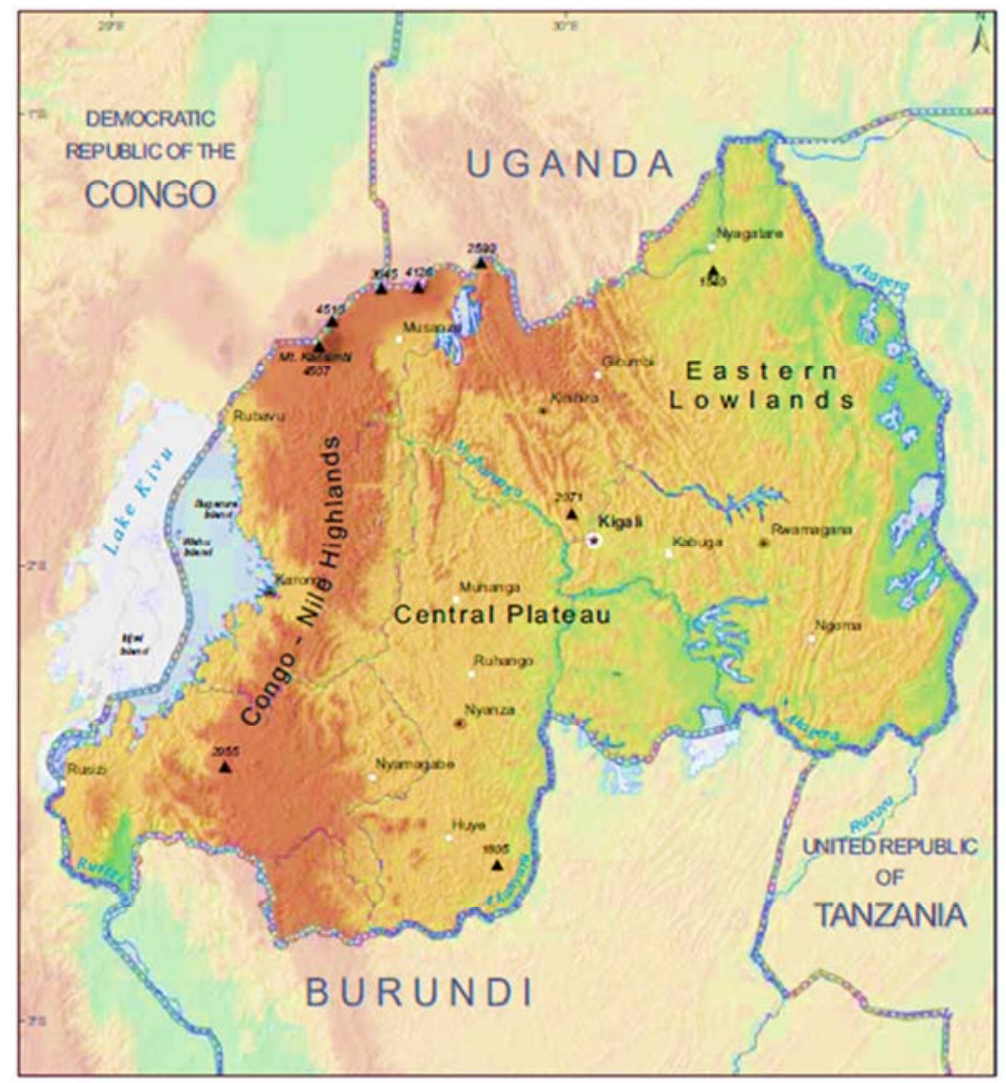

Figure 1. Rwanda's terrain map. Source: [6].

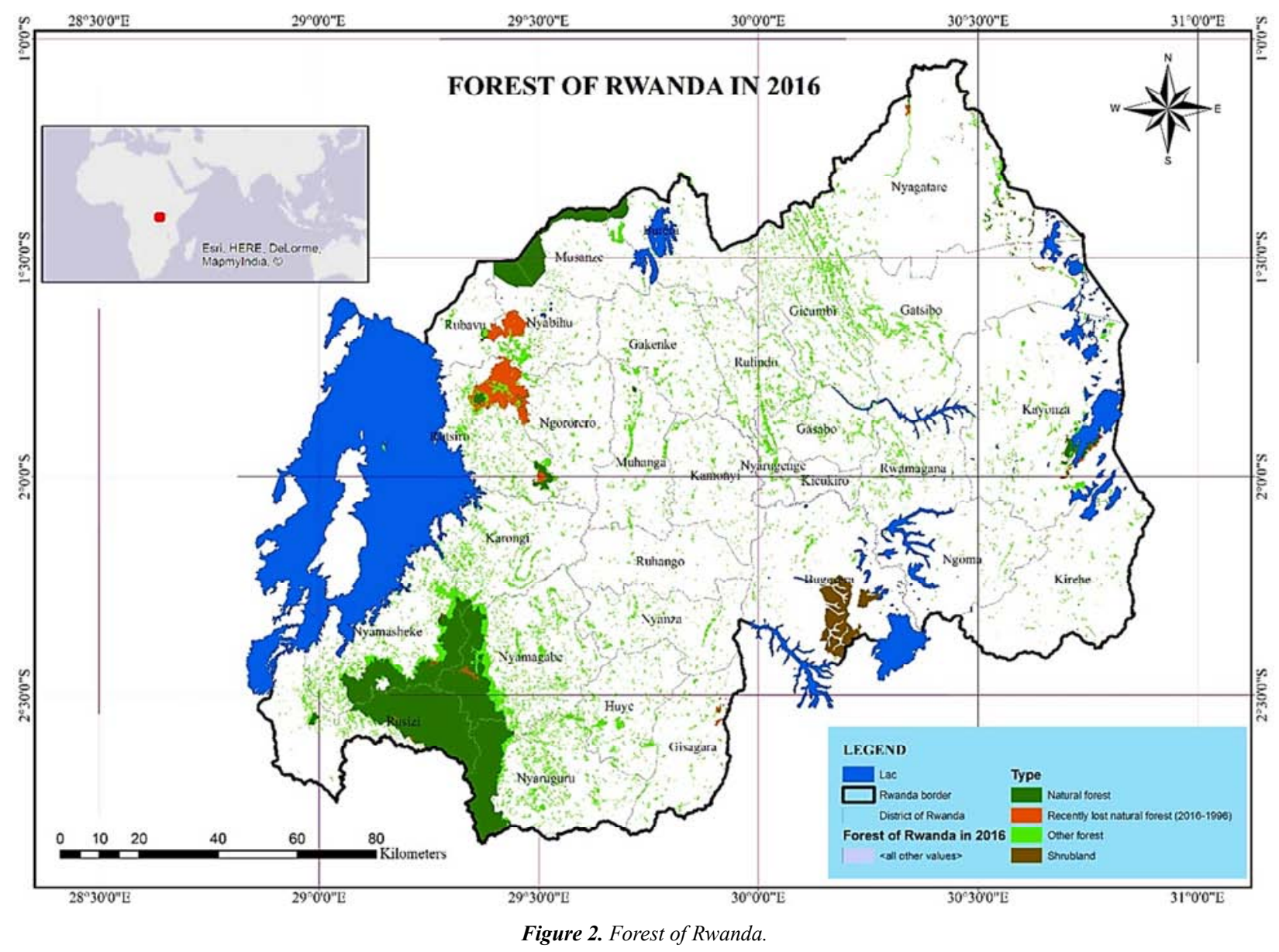


Table 1. Climatic conditions summary in Rwanda.

\begin{tabular}{llll}
\hline Parameters & High altitude $(\mathbf{1 , 8 0 0 - 3 , 0 0 0}$ m) & Central plateau (1,500- 1,800 m) & Eastern lowlands (1,250- 1,500 m) \\
\hline Rainfall $(\mathrm{mm})$ & $1,300-2,000$ & $1,200-1,400$ & $600-1,400$ \\
Temperature $\left({ }^{\circ} \mathrm{C}\right)$ & $16-17$ & $18-21$ & $20-54$ \\
Relative Humidity $(\%)$ & $80-95$ & $70-80$ & $50-70$ \\
\hline
\end{tabular}

Table 2. Rwanda's forest expanse 1990-2015.

\begin{tabular}{llllll}
\hline Rwanda's Forest expanse 1990-2015 & & & & \\
\hline Year & $\mathbf{1 9 9 0}$ & $\mathbf{2 0 0 0}$ & $\mathbf{2 0 0 5}$ & $\mathbf{2 0 1 0}$ & $\mathbf{2 0 1 5}$ \\
\hline Forest area (Area in Sqkm) & 3,180 & 3,440 & 3,850 & 4,460 & 4,800 \\
Primary forest (Area in Sqkm) & 70 & 70 & 70 & 70 & 70 \\
other naturally regenerated forest (Area in Sqkm) & 630 & 550 & 550 & 550 & 550 \\
Planted forest (Area in Sqkm) & 2,400 & 2,820 & 3,230 & 3,840 & 4,180 \\
\hline
\end{tabular}

The planted forest area is the biggest and it occupies $87.1 \%$ of the total forest. The naturally regenerated forest has decreased between the years 1999 and 2015 at a rate of 3 Sqkm per year contrary to the planted forest which has known an increase of 6.8 ha per year during the same period.

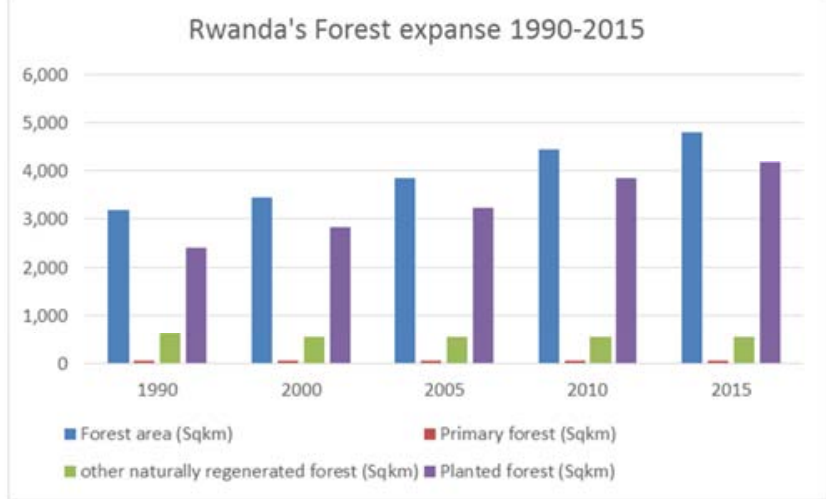

Figure 3. Rwanda's Forest expanse change (1990-2015).

\subsection{Criteria of Selection}

The choice of forest plantation site is a collective decision in general, that involves different groups of people including foresters, government policy makers, planting teams and forest managers. The decision is made according to the information concerning the proposed plantation site. The objective is to select the plantation site that will easily allow the quick and sustainable establishment of a forest plantation. Information gathering on site is necessary in order to determine whether the land is really suited for forest plantations according to the criteria set. Site data gathering also may help in minimizing errors that may occur otherwise. After the establishment of the forest plantation site, it is necessary to delimit the area by setting the boundaries. When the area may be intruded with dangers like animals, it is better to put a boundary fence. When choosing the forest plantations site, there a minimum of environmental and location factors that must be considered. The general factors include, temperatures, rainfalls, elevation and slope. On one side, lower temperature can affect forest plantation because the decrease of photosynthetic rate lead to the reduction of carbon gain and the growth rate of the tree. On the other side,
Higher rainfall are favorable for the trees because it helps to accelerate the growth rate [16].

\subsubsection{Land Use}

Land use refers to the functional aspect of a land. It reflects the extent to which human activities affect a certain area, in using land and its resources [17]. Considering land use in proposing new area for forests plantation is necessary because land use is an important factor in insuring sustainability. In this study, non-agricultural lands, nonhabitable lands, area without roads, lands that are not covered by forests are considered. Water bodies were also excluded. Areas with forests have been excluded for suitability test because, afforestation in those areas may results in deforestation as previous studies have shown that forest expansion may be a threat to the environment and biodiversity in general because it may involve the removal of natural forest that was already in place [13]. Unlike the author of [18] who showed that forest plantations should be established in areas of agriculture of subsistence, for this study such areas are not included because most of Rwandan farmers practice agriculture of subsistence.

\subsubsection{Slope}

The slope of a terrain indicates the variations in elevation. Although some studies have stated that the terrain slope has a small impact on the height of the forest and a big impact on the volume [19], others have proved that the slope is an important factor in the density, growth, biomass and structure of a vegetation [20], [21]. For forest plantations in Rwanda, the slope must be taken into consideration in order to assure the smooth growth of forest plantations and maximize the future benefits of a well-maintained forest. The figure bellow shows the land slope analysis of Rwanda. It identifies lands with a slope less than $10 \%$, slope between $20 \%$ and $30 \%$, between $30 \%$ and $40 \%$ and more than $40 \%$ in Rwanda. The slope in percentage is normally calculated by multiplying by 100 the quotient of the difference in elevations of two points by the distance between them.

$$
\frac{\text { Difference in elevations }}{\text { Distance }} \times 100
$$




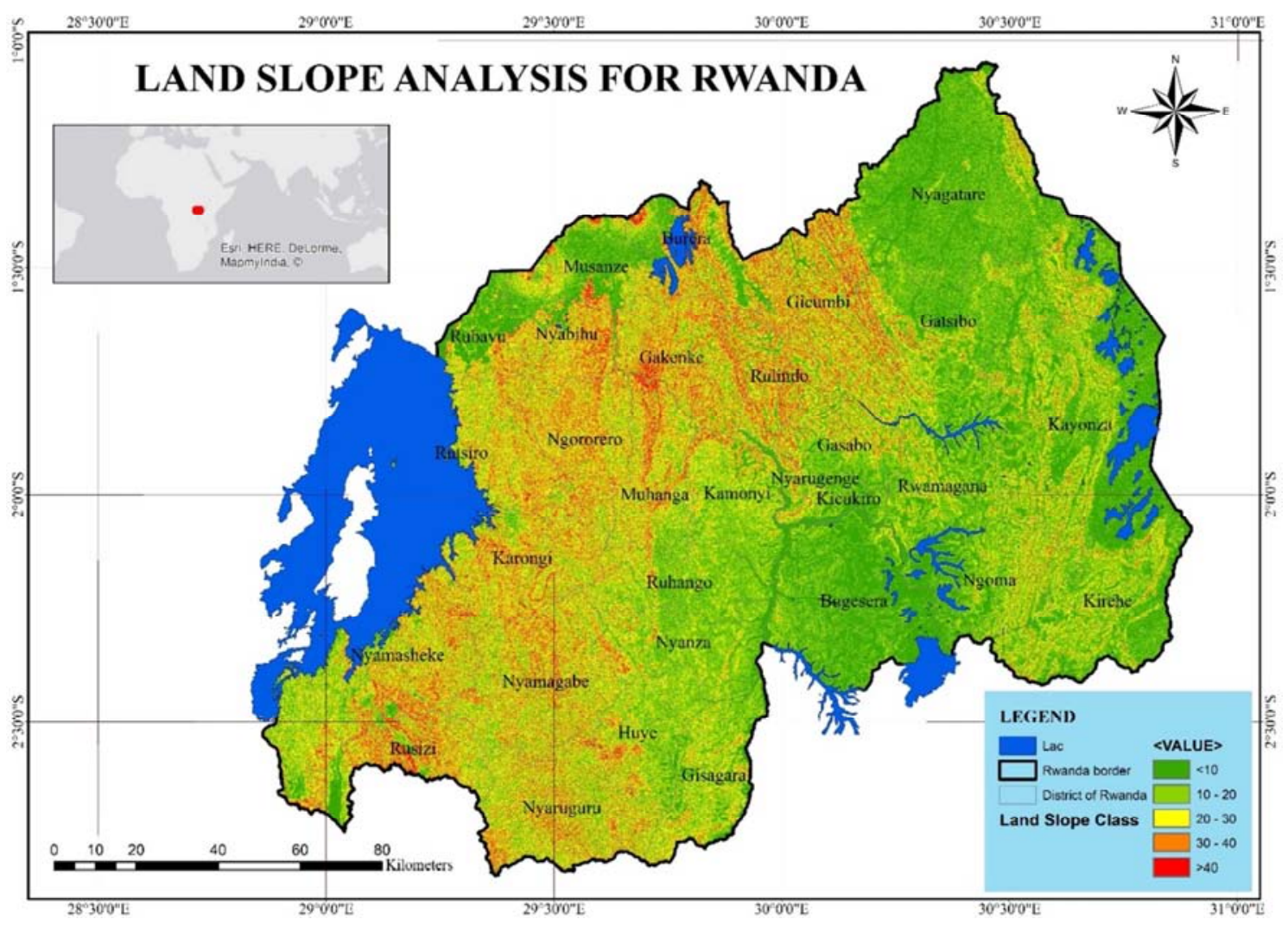

Figure 4. Land slope analysis.

Regions with high slope are not appropriate to agriculture because the moving of agricultural machine is not facilitated. A certain percentage of Rwanda's land has a slope more than $30 \%$, but some areas with that slope might already be occupied by other activities. In this study, considered lands with a slope of $30 \%$ and more are considered for the proposition of forest plantation.

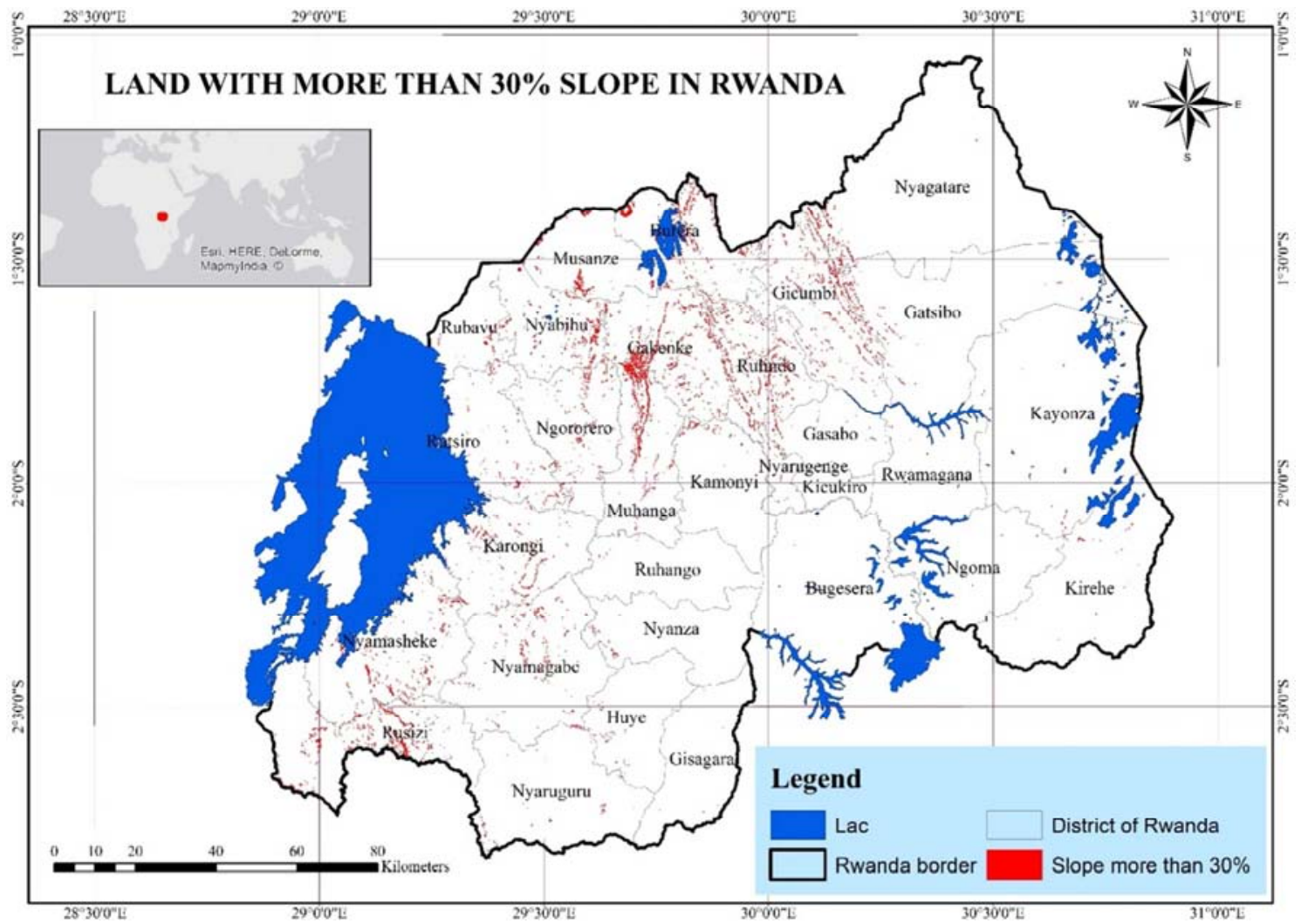

Figure 5. Land with more than 30\% slope in Rwanda. 


\subsubsection{Elevation}

Rwanda has a relatively elevated lands of East and Central Africa, with high mountains which give it an average elevation of 1,700 meters. Although Rwanda has got high mountains in general, its relief is divided into three geographical regions spanning from West to East. Western and Northern parts of Rwanda have mountains and hills of the Congo-Nile Divide and the volcanoes range in the north. This area has mountains with valleys, with more than 2,000 meters of elevation. The Congo-Nile Divide has 3,000 meters at its uppermost point but the volcanoes range makes it small, because its highest peak, Kalisimbi, is 4,507 meters long. Rwanda is well known as "Land of a Thousand Hills" because of its mountainous terrain. The average elevation of the central part of Rwanda varies between 1,500 and 2,000 meters. The eastern part which is elevated at less than 1,500 meters in average, is composed by relatively flat lands with small hills and valleys [22].

Because of its elevated relief, the climate in Rwanda is a temperate one, with yearly temperature of $18.5^{\circ} \mathrm{C}$ in average. It has two rainy seasons over the year which give it the average rainfall of 1,250 millimeters. The rainfall varies over the country and it depends on the terrain. In their research, the authors [23] have shown the existence of a relationship between the elevation and the temporal rainfall of a given area. The rainfall is much more important in the elevated regions of west and north-west with an average of 1,600 millimeters. It decreases in the center of the country with an annual rainfall between 1,000 and 1,300 millimeters and again decreases over the east part where it is below 1,000 millimeters.

The variation in topography of Rwanda which influences its rainfall amount distribution, has also an influence on forest distribution of Rwanda. Natural forests are found in the West and North-west of Rwanda, a region with high mountains and high rainfall amount.

Although Rwanda enjoys more or less constant temperatures, the climate is known to vary from year to year, with extreme variations in rainfall sometimes resulting in flooding. These extreme variations have a profound impact on agricultural production, which sometimes falls into recession.

\subsubsection{Climate}

A specified range of temperature varying between $15{ }^{\circ} \mathrm{C}$ and $25^{\circ} \mathrm{C}$ throughout the year, is a land use requirement if it is being employed to describe the conditions necessary for a particular tree species [12].The temperature in Rwanda varies according to the topography of the country and the rainfall amount varies in the same way. Areas of high altitude have lower temperatures and a big amount of rainfalls. According to [24], forests are denser and bigger in number in wet regions that they are in dry regions.

Despite its location at only two degrees at the south of the Equator, Rwanda's high altitude makes the climate temperate. The daily temperature in average near Lake Kivu, at an altitude of $1,463 \mathrm{~m}$ reaches $22.8^{\circ} \mathrm{C}$. During the two seasons of rain identified in Rwanda, (February-May and September-December), heavy rainstorms occur almost daily in alternation with sunny weather. Annual rainfall which is about $800 \mathrm{~mm}$ in average, and is commonly higher in the western and north-western high mountains than in the eastern lowlands. When the temperature is elevated and precipitations decrease, the situation is then not favorable to the forest [25].

Climatic conditions must be taken into considerations because they have a big impact on forests as seen above. Regions with relatively low temperature and elevated amount of rainfall are considered for the purpose of this study. In addition, tree species with biological properties related to such climate, elevation and slope should be considered.

\section{Results and Discussion}

According to the results of analysis conducted, highly suitable areas for forest plantations and other areas which are not suitable for forest plantations have been identified. Rwanda's elevation ranges between $915 \mathrm{~m}$ and $4500 \mathrm{~m}$, with the north-west part of the country being the most highly elevated. According to the results of slope analysis in Rwanda, areas suitable for new forest plantations have been identified.

Those are non-forested areas with a slope over $30 \%$. The results show that in Rwanda, $33.36 \%$ of the total area of the country are lands with a slope between $10-20 \%$ which occupy the high percentage. $31.58 \%$ of the total area of the country are lands with a slope less than $10 \%$. The country's lands area with a slope between $20-30 \%$ span $19.9 \%$ of the total area of Rwanda. The target slope for the purpose of this study is more than $30 \%$. Results shows that the lands area with a slope between $30-40 \%$ occupy $11.6 \%$ of the total area of the country and the slope over $40 \%$ is only $3.46 \%$. The results of the analysis are summarized in the table below.

Table 3. Slope Classes.

\begin{tabular}{lll}
\hline Slope & AREA $(\mathbf{S q k m})$ & PERCENTAGE $(\%)$ \\
\hline$<10$ & 8319.41421823188 & 31.58711450464 \\
$10-20$ & 8787.33757185647 & 33.36372379018 \\
$20-30$ & 5241.34850493392 & 19.90032844154 \\
$30-40$ & 3076.69560687983 & 11.68158404921 \\
$>40$ & 913.20409809793 & 3.46724921444 \\
\hline
\end{tabular}

Table 4. Forested land and non-forested land of Slope over $30 \%$.

\begin{tabular}{ll}
\hline Forested land: & 1382.80371374817 \\
Unforested land: & 2607.09599122958 \\
\hline
\end{tabular}

The map showing the availability of the suitable lands for forest plantation has been produced and it shows the nonforested lands with slope over $30 \%$ which is the target for this study. Among the total lands of slope over than $30 \%$, some areas are already forested and therefore not appropriate for new forest plantations. The total area of forested lands with a slope over $30 \%$ is $5.25 \%$ of the total area of the country. 


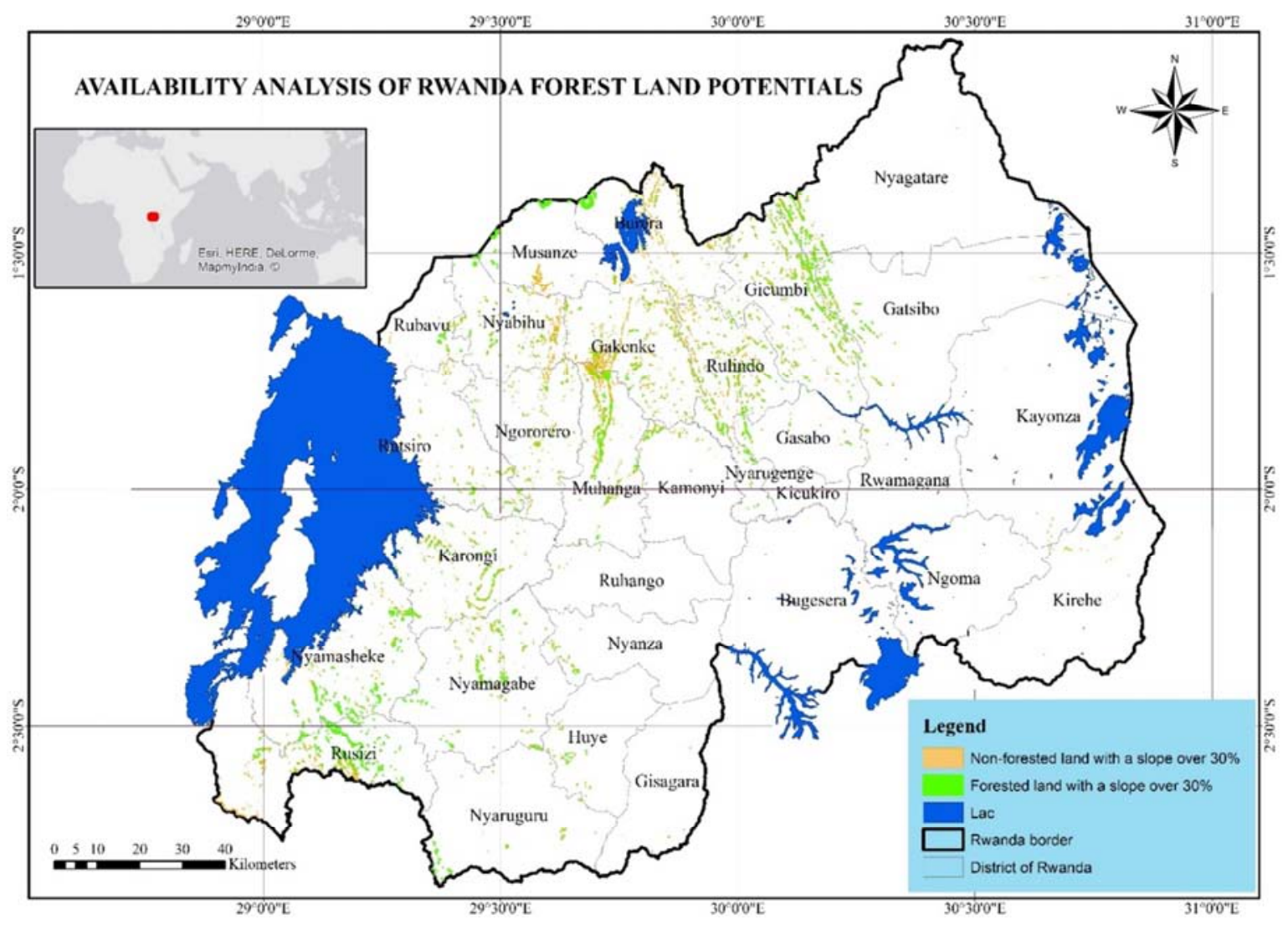

Figure 6. Availability analysis of Rwanda forest land potentials.

The highly suitable lands areas that were found after the analysis, are areas which have a slope more than $30 \%$ and are non-forested. The total expanse of the lands satisfying the criteria occupies $9.89 \%$ of the total land area of the country.

As stated in their report [8] human activities including agriculture, mining activities, frequent forest fires and urbanization are the major drives deforestation and forest degradation. Rwanda has known a significant decrease in forests between the year 1990 and 2000 due to the refugee's settlements and returnee's settlement that followed people's displacement due to conflicts and genocide. Like in many other African countries, fuel wood collection is also one of the deforestation drives.

In their research [26], the authors mentioned that forest plantation sometimes is driven by economic factors. As natural forests are destructed, new forests are planted for timber production.

Establishing new forest plantations in Rwanda, on the slope greater than $30 \%$ is beneficial to Rwanda's environment protection because the plantations roots will help in strengthening the soil and avoid landslides during the two rain periods. At a regional level forest plantation can be beneficial for the environment by protecting against wind erosion. The role of forest plantations in protecting endangered plants and animals' species is also undeniable.

Planting new forests in Rwanda may also bring a social benefit for local people by providing recreational and tourist centers. For some people, forests have an important cultural and spiritual value and there is a need of appropriate forests for meditation and escaping to polluted urban air. Non-wood forests plantations may be beneficial to the society as they may be used as food or as medicinal plants.

\section{Conclusion}

The plantation of forest in the identified suitable regions will bring economic, social and environmental benefits. Economically, the more tree plantations are available, the more is timber production and creation of employment are developed. Forest areas can provide recreational centers for neighboring people and forest are beneficial for climate regulation and biodiversity conservation.

Plantation forests can provide most goods and services that are provided by natural forests. These include timber and nontimber forest products, protection of clean water and clean air, soil erosion control, biodiversity, esthetics, carbon sequestration, and climate control. Nonetheless, as the value of environmental services from natural forests is higher than that from forest plantations, the demand for conservation of natural forests is stronger.

Forest plantations can be commercialized because they are able to supply timber, fiber, firewood and non-timber forest products for industrial and non-industrial use. Forest products have a higher benefit compared to other products (concrete, plastic and metal) because they are renewable and are good for the environmental protection. Planted forests, when responsibly managed, can also contribute to the environmental protection (soil and water protection, 
rehabilitation of degraded lands, landscape restoration, habitant development and carbon sequestration), and also social services as well, and also support the subsistence means of the population (regional development, income generation, employment and recreation); these can also alleviate the pressure exercised upon primary forests and other valuable forest ecosystems.

Forest areas dedicated to production has been increasing between years 1990-2015 where the annual change rate was of 5,400 ha $(1.9 \%)$. Planting new forest on the proposed lands will help to increase this rate and increase the value of forest products. It is beneficial for Rwanda because it will reduce pressure to the natural forests which otherwise would be in danger. Forest plantations grow more quickly than natural forest and it is an advantage for timber production.

The identified areas suitable for new forest plantation can help the government to extend the existing forest areas in Rwanda. These areas are mainly located in the north and west part of Rwanda even though they can be found all over the country. The government should lunch particular projects in the district with land of slope between $30 \%-40 \%$ in order to follow up the afforestation of these areas.

In order to encourage the forest plantations in Rwanda, there should be no government support for maintained agricultural production for lands with a slope exceeding 30 degrees. Program for tree planting should be provided for land owners who want to change existing farmland towards forestry land use.

\section{References}

[1] NISR, "EICV4 - Environment and natural resources thematic Report," 2016.

[2] "Worldometers," 10 September 2018. [Online]. Available: http://www.worldometers.info/world-population/rwandapopulation/.

[3] B. E. Sawe, "African Countries By Population Density," 1 August 2017. [Online]. Available:

https://www.worldatlas.com/articles/african-countries-bypopulation-density.html.

[4] FAO, "Global forest resources assessment 2020: Terms and definitions FRA 2020," Rome, 2018.

[5] FAO, "Global forest ressources assessment 2015," Food and Agriculture Organization of the United Nations, Rome, 2015.

[6] UNEP, "Rwanda: From Post-Conflict to Environmentally Sustainable Development," United Nations Environment Programme, 2011.

[7] S. S. Pandey, G. Cockfield and T. N. Maraseni, "Major drivers of deforestation and forest degradation in developing countries and REDD+," Int. J. for Usuf. Mngt, pp. 99-107, 2013.

[8] G. Kissinger, . M. Herold and V. De Sy, " Driver of deforestation and forest degradation: A Synthesis Report for REDD+ Policymakers," Lexeme Consulting, Vancouver, 2012.

[9] R. Sidle, "The Role of Environmental Management and EcoEngineering in Disaster Risk Reduction and Climate Change Adaptation," ProAct Network, Gokasho, 2008.
[10] FAO, "Global Forest Resources Assessment 2010: Socioeconomic functions of forest resources," 2010.

[11] FAO, "The State of the World's Forests 2018 - Forest pathways to sustainable development," Rome, 2018.

[12] FAO, "Land evaluation for forestry," Rome, 1984.

[13] L. L. Bremer and K. A. Farley, "Does plantation forestry restore biodiversity or create green deserts? A synthesis of the effects of land-use transitions on plant species richness," Biodivers Conserv, p. 3893-3915, 2010.

[14] A. M. Kandari, S. Kasim, M. A. Limi and J. Karim, "Land Suitability Evaluation for Plantation Forest Development Based on Multi-criteria Approach," Agriculture, Forestry and Fisheries, vol. 4, no. 5, pp. 228-238, 2015.

[15] H. Akıncı, A. Y. Özalp and B. Turgut, "Agricultural land use suitability analysis using GIS and AHP technique," Computers and Electronics in Agriculture, vol. 97, pp. 71-82, 2013.

[16] D. Kambo and R. K. Danby , "Factors influencing the establishment and growth of tree seedlings at Subarctic alpine treelines," Ecosphere, vol. 9, no. 4, pp. 1-17, 2018.

[17] X. Gong, L. G. Marklund and S. Tsuji, "Land Use Classification," 14th Meeting of the London Group on Environmental Accounting, 2009.

[18] T. V. Holt, M. W. Binford, K. M. Portier and R. Vergara, "A stand of trees does not a forest make: Tree plantations and foresttransitions transitions," Land Use Policy, vol. 56, p. 147-157, 2016.

[19] H. O. Ørka, O. M. Bollandsås, E. H. Hansen, E. Næsset and T. Gobakken, "Effects of terrain slope and aspect on the error of ALS-based predictions of forest attributes," Forestry, pp. 1-13, 2017.

[20] I. Albaba, "The effects of slope orientations on vegetation characteristics of Wadi Alquf forest reserve (WAFR) West Bank-Palestine," International Journal of Agricultural and Soil Science, vol. 2, no. 7, pp. 118-125, 2014.

[21] S. Hu, i. Ma, H. H. Shugart and X. Yan, "Evaluating the impacts of slope aspect on forest dynamic succession in Northwest China based on FAREAST model," Environmental Research Letters, 2018.

[22] McSweeney, Robert, "Rwanda's Climate: Observations and Projections," Smith School of Enterprise and the Environment, 2011.

[23] D. Ntwali, B. A. Ogwang and V. Ongoma, "The impact of topography on spatial and temporal rainfall distribution over Rwanda based on WRF model," Atmospheric and Climate Sciences, vol. 6, pp. 146-157, 2016.

[24] F. Belda and J. Melia, "Relationships between climatic parameters and forest vegetation: application to burned area in Alicante (Spain)," Forest Ecology and Management, vol. 135, pp. 195-204, 2000.

[25] I. Machar, V. Vlckova, A. Bucek, V. Vozenilek, L. Salek and L. Jerabkova, "Modelling of Climate Conditions in Forest Vegetation Zones as a Support Tool for Forest Management Strategy in European Beech Dominated Forests," Forests, vol. 8, no. 81, pp. 1-17, 2017.

[26] D. Zhang and J. Stanturf, "Forest plantation," Ecosystems, pp. 1673-1680, 2008. 